\title{
Terahertz Time-Domain Spectroscopy and Imaging using Compact Fiber-coupled Terahertz Modules
}

\author{
Young-Jong Yoon ${ }^{1,2}$, Namje Kim ${ }^{1}$, Han-Cheol Ryu ${ }^{3}$, Kiwon Moon ${ }^{1}$, Jun-Hwan Shin ${ }^{1,2}$, \\ Sang-Pil Han ${ }^{1,2 \dagger}$, and Kyung Hyun Park ${ }^{1,2}$ \\ ${ }^{1} \mathrm{THz}$ Photonics Creative Research Center, ETRI, Daejeon 305-700, Korea \\ ${ }^{2}$ School of Advanced Device Technology, UST, Daejeon 305-350, Korea \\ ${ }^{3}$ Department of Car Mechatronics, Sahmyook University, Seoul 139-742, Korea
}

(Received February 3, 2014; Revised manuscript February 24, 2014; Accepted February 24, 2014)

We have demonstrated a terahertz (THz) time-domain spectroscopy and imaging system using compact fiber-coupled THz modules. Using this $\mathrm{THz}$ spectroscopy system we have measured the absorption spectrum of water vapor in free space over 3 $\mathrm{THz}$, as well as the refractive indices of various substrates such as $\mathrm{Si}, \mathrm{Al}_{2} \mathrm{O}_{3}$, and $\mathrm{GaAs}$ using the transfer-function method. Through the THz imaging system we have observed a high-quality THz image of a medical knife and metal clip sample, with a resolution of $192 \times 89$ pixels using a step size of $250 \mu \mathrm{m}$.

Keywords: THz time domain spectroscopy(THz-TDS), Refractive index, THz image detection

OCIS codes : (300.6495) Spectroscopy, terahertz; (260.5150) Photoconductivity; (120.4290) Nondestructive testing; (110.2970) Image detection systems

\section{초소형의 광섬유 결합형 테라헤르츠 모듈을 이용한 시간영역에서의 분광 및 이미징}

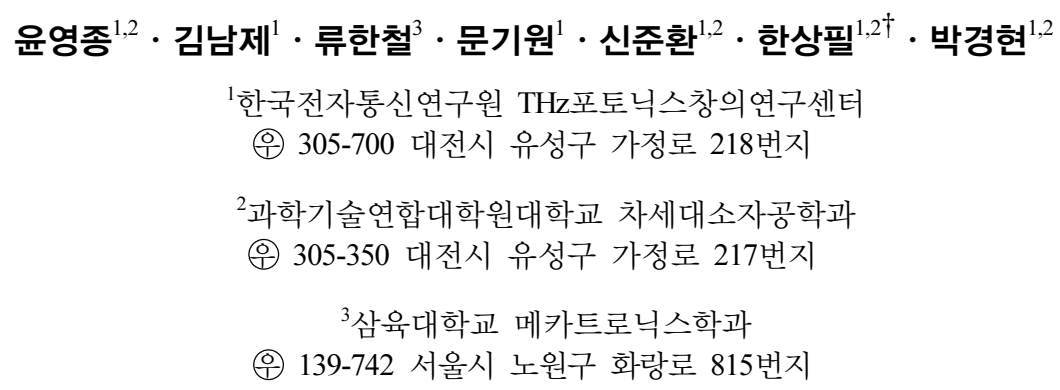

(2014년 2월 3일 받음, 2014년 2월 24일 수정본 받음, 2014년 2월 24일 게재 확정)

본 논문에서는 초소형의 광섬유 결합형 테라헤르츠 모듈을 이용하여 테라헤르츠 시간영역 분광 및 영상 시스템을 구성하였다. 구성된 $\mathrm{THz}$ 분광 시스템을 이용하여 $3 \mathrm{THz}$ 이상의 자유공간에 분포되어 있는 수분의 고유 흡수 스펙트럼을 관측하였고 테라헤르 츠 대역에서의 $\mathrm{Si}, \mathrm{Al} 2 \mathrm{O} 3, \mathrm{GaAs}$ 기판에 대한 굴절률을 측정하였으며 측정을 위해 다중 반사를 고려한 전달 함수를 이용한 굴절률 측정 방법을 이용하였다. 또한, 테라헤르츠 영상 시스템을 이용하여 의료용 칼과 클립을 측정하여 $250 \mu \mathrm{m}$ 간격으로 $192 \times 89$ 픽셀의 영상을 얻었다.

Keywords: 테라헤르츠 시간영역 분광 시스템 (THz-TDS), 굴절률, $\mathrm{THz}$ 영상 측정

OCIS codes : (300.6495) Spectroscopy, terahertz; (260.5150) Photoconductivity; (120.4290) Nondestructive testing; (110.2970) Image detection systems

\footnotetext{
${ }^{\dagger}$ E-mail: sphan@etri.re.kr

Color versions of one or more of the figures in this paper are available online.
} 


\section{I. 서 론}

테라헤르츠(THz) 파는 전자기파 스펙트럼 영역에서 마이 크로웨이브와 적외선 영역 사이의 일반적으로 $0.1 \sim 10 \mathrm{THz}$ 에 해당하는 파를 말하며, 적외선이 가지는 직진성과 마이크로 웨이브가 가지는 다양한 비전도성 물질(옷, 종이, 나무, 플라 스틱, 벽돌) 등을 투과하는 독특한 특성을 가진다. 이 영역은 기술적 한계에 의해 전자기파 스펙트럼 중 가장 접근하기 어 려운 영역으로 알려져 왔다. 하지만 펨토초 레이저와 재료기 술, 공정기술 등의 발전으로 다양한 $\mathrm{THz}$ 파원들이 등장하였 고 이 분야는 지속적으로 발전해 왔다. 물질의 원자나 분자 를 이온화 시키는 X선 과는 달리 그 에너지가 $4.135 \mathrm{meV}$ 정 도로 낮아서 투과하는 물질을 파괴 시키지 않는 비이온화 (non-ionizing), 비파괴 특성을 가지며 기존의 분광기법으로 탐지할 수 없는 주파수 대역에서 물질 고유의 흡수 스펙트 럼, 물리적 특성을 확인할 수 있다. 이러한 특성은 $\mathrm{THz}$ 파를 이용한 분광 및 영상 기술로 발전시켰고 기판검사, 금지약물 이나 위험물에 대한 모니터링, 암세포 분별 등의 보안, 의료, 환경, 비파괴 검사 분야에 활용될 수 있는 가능성을 보여 주 었다 ${ }^{[1]}$.

대부분의 경우 $\mathrm{THz}$ 시스템은 광학계를 이용하여 구성되며 시스템의 크기가 비교적 커서 이동성이 좋지 않다. 하지만 $\mathrm{THz}$ 시스템의 활용도가 높아질수록 동적 환경에서 이용 가 능한 $\mathrm{THz}$ 시스템이 필요하며 이를 위해 이동성이 좋은 소형 의 $\mathrm{THz}$ 시스템에 대한 지속적인 연구가 진행 중이다 ${ }^{[2-4]}$. 현 재 연구되는 소형의 $\mathrm{THz}$ 발생 및 검출 시스템들은 광섬유와 광전도 안테나가 하나의 모듈로 구성되어 있는 형태로 이동 성이 좋고, 광통신용 레이저를 이용하므로 저렴하게 구성할 수 있으며 안정적으로 $\mathrm{THz}$ 펄스파 및 연속파 발생 및 검출 이 가능하다 ${ }^{[3-8]}$.

본 연구에서는 먼저, 초소형 크기의 광섬유 결합형 $\mathrm{THz}$ 발 생 및 검출 모듈을 자체 제작한 후, 이를 이용하여 $\mathrm{THz}$ 분광 및 영상 시스템을 구축하였다. 그리고 이를 이용하여 시료 $\mathrm{Al}_{2} \mathrm{O}_{3}$ 기판의 굴절률 및 흡수율을 Newton-Raphson 방법을 이용하여 측정하였고 또한 의료용 칼과 클립의 2 차원 스캔 을 통한 $\mathrm{THz}$ 이미지를 측정하였다.

\section{II. 광섬유 결합형 $\mathrm{THz}$ 모듈 및 분광 시스템}

그림 1 은 자체 개발된 $\mathrm{THz}$ 파 발생 및 검출기 모듈이다. 모 은 $\mathrm{THz}$ 발생 및 검출에 필요한 광전도 안테나와 서브 마운 트, 모듈 하우징, 고저항 실리콘렌즈, 단일모드 광섬유, 동축 케이블이 하나의 모듈로 구성되어 있다. 모듈에 이용한 광전 도 안테나는 $\mathrm{InP}$ 기판 위에 $\mathrm{Be}$ 가 도핑된 $\mathrm{InGaAs}$ 층을 $1.2 \mu \mathrm{m}$ 두께로 성장시켜 활성층으로 이용하였고 광전도층의 운반자 수명시간은 대략 $1.7 \mathrm{ps}$ 이다. 안테나는 log-spiral 형태이며 안테나 중앙에 $10 \times 10 \mu \mathrm{m}^{2}$ 크기의 활성층이 있다. 서브마운 트는 광전도 안테나를 지지하는 역할로 광전도 안테나에 외 부 바이어스를 인가하고 레이저 펄스가 안테나의 활성영역
에 도달할 수 있도록 설계하였다. 모듈에서는 광전류의 증가 로 인한 열을 효과적으로 방출하기 위해 방열효율이 우수한 Aluminium nitride(AIN) 서브마운트를 이용하였고 ${ }^{[3]}$, 고저항 실리콘 렌즈를 이용하여 자유공간으로 방사되는 $\mathrm{THz}$ 파의 손 실을 줄이고 원하는 방향으로 $\mathrm{THz}$ 파가 진행되도록 하였다. 모듈 하우징을 이용하여 구성요소들을 고정시켰으며, 완성된 모듈의 부피는 $0.7 \mathrm{cc}$ 이다.

위와 같은 초소형의 광섬유 결합형 $\mathrm{THz}$ 모듈을 이용한 $\mathrm{THz}-\mathrm{TDS}$ 시스템은 그림 2와 같다. 본 시스템은 중심파장이 $1.55 \mu \mathrm{m}$ 이며 펄스폭이 $70 \mathrm{fs}$, 반복율이 $100 \mathrm{MHz}$ 인 펨토초 레이저와, 단일모드 광섬유(SMF; single-mode fiber), 분산보 상 광섬유(DCF; dispersion compensated fiber), $1 \times 2$ 광분배기 (1×2 splitter), THz 모듈, 시간지연기(delay line), 함수발생기 (function generator), Lock-in 증폭기(lock-in amplifier)로 구 성되어 있으며, 두 개의 $\mathrm{THz}$ 모듈을 각각 $\mathrm{THz}$ 발생기와 검 출기로 이용하였다. 펨토초 레이저에서 발생된 펄스를 광섬 유에 입사한다. 입사된 $1.55 \mu \mathrm{m}$ 파장의 광은 광섬유를 진행

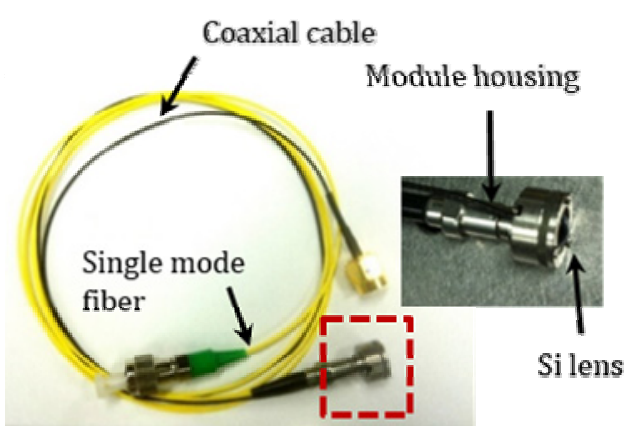

FIG. 1. Photograph of a compact fiber-coupled THz module.

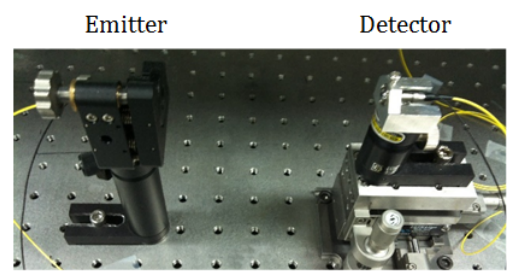

(a)

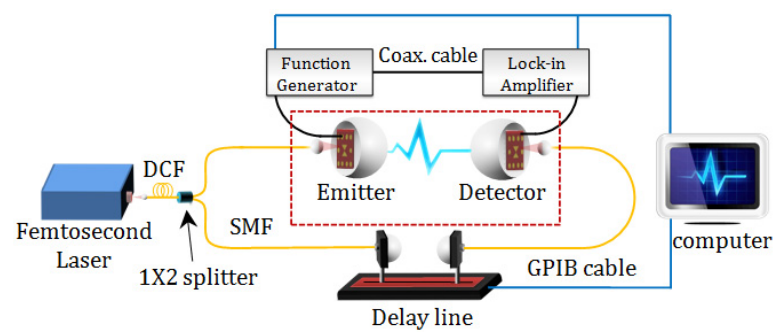

(b)

FIG. 2. (a) Photograph of $\mathrm{THz}$ emitter and detector modules and (b) $\mathrm{THz}$ time-domain spectroscopy setup using the $\mathrm{THz}$ modules (DCF: dispersion compensated fiber, SMF: single-mode fiber, GPIB: general-purpose interface bus). 
할 때 분산이 발생하므로 분산 보상 광섬유를 이용하여 레이 저 펄스의 분산을 최소화하였다. 실제 시스템에서는 $6 \mathrm{~m}$ 길 이의 광섬유와 광학계 등에서 발생되는 분산을 보상하기 위 하여 $1.3 \mathrm{~m}$ 길이의 분산보상 광섬유를 장착하였다. 입사된 펨토초 펄스가 $1 \times 2$ 광분배기를 지나면 두 개의 광으로 나누 고 각각 $\mathrm{THz}$ 발생기와 검출기에 전달시켜 내부에 있는 광전 도안테나의 활성층을 여기시킨다. $\mathrm{THz}$ 발생기에서는 여기된 광전도안테나에 외부 바이어스를 인가하여 $\mathrm{THz}$ 펄스를 생성 시키고 $\mathrm{THz}$ 검출기에서는 Lock-in 증폭기를 이용하여 자유 공간을 통해 전달된 $\mathrm{THz}$ 펄스를 호모다인 검파방법으로 측 정하였다. 또한 계측 장비의 작동 및 데이터 수집은 상용 소 프트웨어인 Labview(National Instruments Co.) 를 이용하였다.

$\mathrm{THz}-\mathrm{TDS}$ 시스템으로 자유공간에서 측정한 $\mathrm{THz}$ 펄스파의 실험 결과를 그림 3 에 나타내었다. 발생기와 검출기 사이의 자유공간의 거리는 $70 \mathrm{~mm}$ 이며, 발생기와 검출기에 도달한 펄스광의 세기는 각각 평균 $11 \mathrm{dBm}, 8 \mathrm{dBm}$ 이다. $\mathrm{THz}$ 발생 기에 진폭 $6.5 \mathrm{~V}$ 의 사인파를 바이어스로 인가했으며 이 때 발생한 광전류는 약 $0.5 \mathrm{~mA}$ 이다. 그림 3(a)는 광섬유 결합 형 THz-TDS 시스템을 이용하여 자유공간에서 측정한 시간 영역에서의 $\mathrm{THz}$ 의 신호이다. 측정 신호에서 나타나는 다중

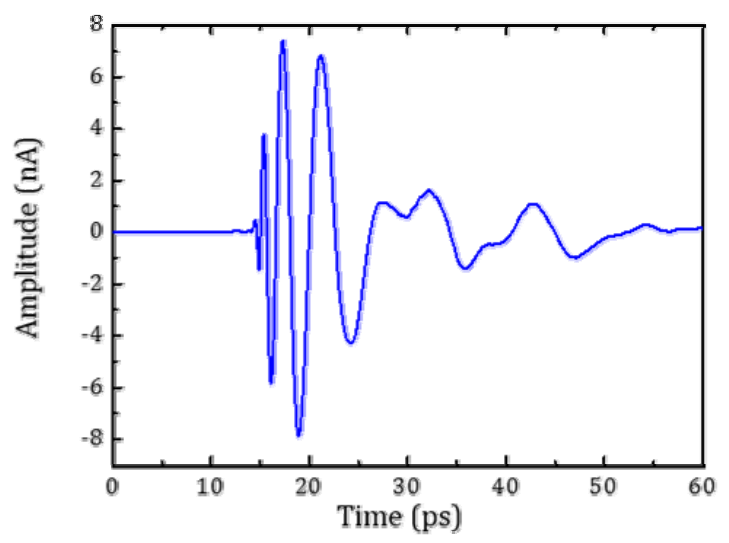

(a)

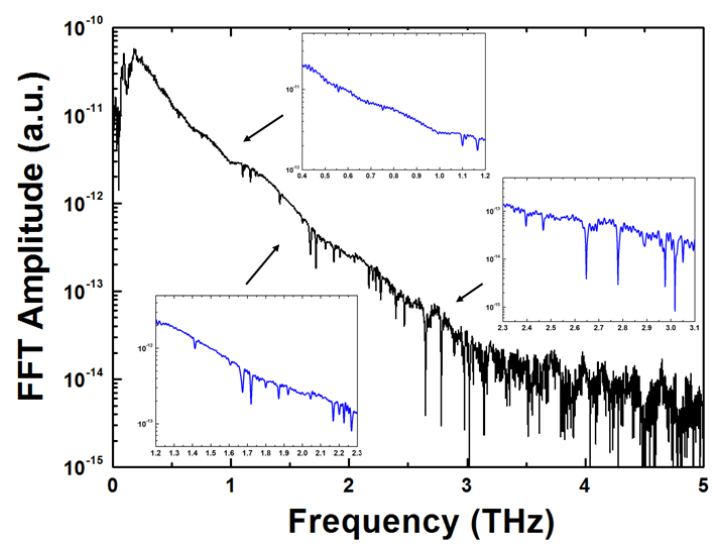

(b)

FIG. 3. (a) Time domain trace of a THz electric field and (b) its FFT amplitude spectrum in free space.
피크는 $\log$-spiral 안테나에서 나타나는 특징이며, 신호 지속 시간은 약 $40 \mathrm{ps}$ 이다. 그림 3(b)는 측정된 시간영역에서의 결 과를 Fast Fourier Transform(FFT)한 자유공간에서의 $\mathrm{THz}$ 주 파수 스펙트럼이다. 이 결과에서 보면 수증기 분자에 포함되 어 있는 하이드록시기(-OH)에 기인된 특정 주파수에서 흡수 피크들을 발견할 수 있다. 이 흡수 피크들이 발견된 주파수 는 $0.56,0.75,0.98,1.11,1.16,1.20,1.23,1.41,1.60,1.67$, $1.71,1.80,1.87,1.92,2.04,2.12,2.16,2.20,2.22,2.26,2.39$, $2.46,2.64,2.77,2.89,2.97,3.01,3.05 \mathrm{THz}$ 로 상온의 자유공 간에 존재하는 수분의 흡수 주파수와 일치하였다 ${ }^{[9,}{ }^{10]}$.

\section{III. $\mathrm{THz}$ 분광 및 이미징 실험결과}

\section{1. $\mathrm{Al}_{2} \mathrm{O}_{3}$ 의 굴절률 측정}

그림 4는 $\mathrm{THz}$ 발생기와 검출기 사이에 시료를 두었을 때 나타나는 $\mathrm{THz}$ 파의 경로이다. 매질1과 매질3은 자유공간이 며 매질2는 시료이다. 발생기에서 발생된 $\mathrm{THz}$ 펄스를 시료 에 입사시키면 자유공간에서 시료를 통과하여 검출기에 도 달한다. $\mathrm{THz}$ 펄스가 각 매질을 지날 때마다 펄스의 일부는 반사하는 특성으로 인해 시료 내부에서 다중 반사가 일어난 다. 광섬유 결합형 $\mathrm{THz}$ 모듈에서 발생된 $\mathrm{THz}$ 펄스의 신호 지속시간은 약 $40 \mathrm{ps}$ 이며 이는 반도체 기판과 같은 얇은 두 께의 시료를 측정할 경우 시료에서 반사되는 시간이 짧아 신 호 지속기간 동안 본신호와 반사된 신호가 함께 측정된다. 그러므로 얇은 두께의 시료의 굴절률 측정 시 반드시 다중 반사가 고려되어야 한다.

$\mathrm{E}_{O}(\omega)$ 는 시료에 입사되기 전 발생기에서 발생된 $\mathrm{THz}$ 펄스 신호의 진폭이며 $\mathrm{E}_{t}(\omega)$ 는 시료를 통과하여 검출기에서 측정 된 $\mathrm{THz}$ 신호의 진폭으로 시료에서 발생된 다중 반사가 포함 된 결과로 측정된다. 측정된 $\mathrm{E}_{t}(\omega)$ 와 $\mathrm{E}_{o}(\omega)$ 를 통해 시료의 투과계수 $\mid T_{\text {meas }}\left(\tilde{n}_{2}, \omega\right)$ 를 구할 수 있으며, 투과계수에 대한

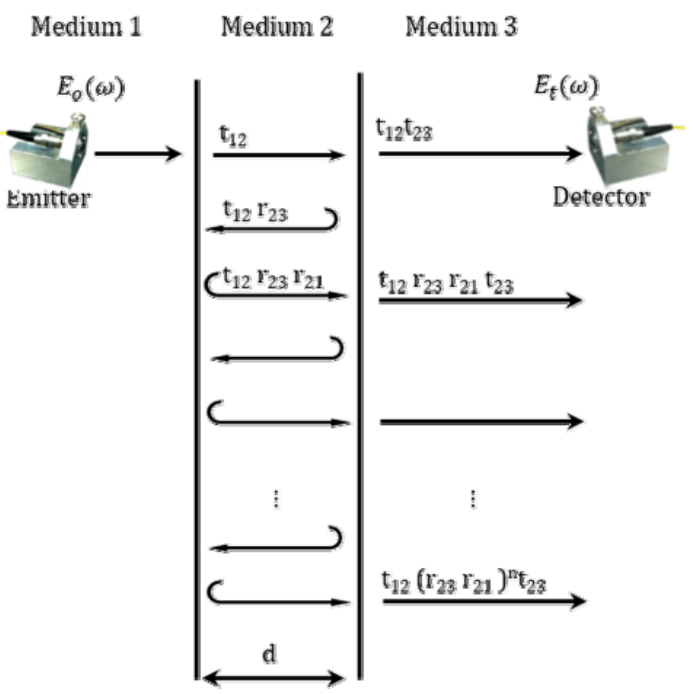

FIG. 4. Schematic diagram of the propagation of a $\mathrm{THz}$ pulse. 
전달함수 $\mid T\left(\tilde{n}_{2}, \omega\right)$ 는 다중 반사에 의한 Fabry-Perot 효과를 고려하여 식 (1)와 같이 정의된다.

$$
T\left(\tilde{n}_{2}, \omega\right)=\frac{E_{t}(\omega)}{E_{o}(\omega)}=\frac{t_{12} t_{23} e^{i\left(\widetilde{n}_{2}-1\right) \omega d / c}}{1-r_{12} r_{23} e^{2 i \tilde{n}_{2} \omega d / c}}
$$

여기서 $r_{12}$ 는 매질 1 과 2 사이의 반사 진폭 계수, $t_{12}$ 는 매질 1 과 2사이의 투과 진폭 계수이며, c는 광속이다. 반사 진폭 계수와 투과 진폭 계수는 각각 식 (2)과 (3)로 정의한다.

$$
\begin{aligned}
& \mathrm{r}_{12}=\frac{\tilde{n}_{1}-\tilde{n}_{2}}{\tilde{n}_{1}+\tilde{n}_{2}} \\
& \mathrm{t}_{12}=\frac{2 \tilde{n}_{1}}{\tilde{n}_{1}+\tilde{n}_{2}}
\end{aligned}
$$

$\tilde{n}$ 은 주파수에 따른 시료의 복소굴절률이며, $\omega$ 는 각주파수 $[\mathrm{rad} / \mathrm{s}], \mathrm{d}$ 는 시료의 두께다. 실험에 사용한 시료는 $\mathrm{Si}(100)$, $\mathrm{Al}_{2} \mathrm{O}_{3}(0001), \mathrm{GaAs}(100)$ 기판이며, 시료의 두께는 각각 300 $\mu \mathrm{m}, 480 \mu \mathrm{m}, 350 \mu \mathrm{m}$ 이다. 굴절률의 계산은 Newton-Raphson 법을 이용하였다 ${ }^{[11,12]}$. $\mathrm{T}\left(\tilde{n}_{2}, \omega\right)$ 와 $\mathrm{T}_{\text {meas }}\left(\tilde{n}_{2}, \omega\right)$ 의 차를 라 정의하고 다음 식과 같이 정의된다.

$$
\sigma_{\rho}=\ln \left(\left|\mathrm{T}\left(\tilde{n}_{2}, \omega\right)\right|\right)-\ln \left(\left|\mathrm{T}_{\text {meas }}\left(\tilde{n}_{2}, \omega\right)\right|\right)
$$

그림 5(a)는 자유공간과 시료를 지나는 $\mathrm{THz}$ 펄스의 시간영 역에서의 신호를 나타낸다. 측정된 $\mathrm{THz}$ 신호의 길이는 약 $40 \mathrm{ps}$ 로 신호에서 발생되는 다중 반사가 본 신호에 묻히기에 충분히 긴 길이이고, 펄스가 시료를 통과할 때 자유공간에 서의 속도보다 줄어들어 시간 지연이 발생하였다. 이렇게 발 생된 시간 지연을 통해 얻어진 시간영역에서의 굴절률을 Newton-Raphson법의 초기값으로 설정하였고, 시간영역 신호 를 각각 $\mathrm{FFT}$ 하여 $\mathrm{E}_{o}(\omega)$ 와 $\mathrm{E}_{t}(\omega)$ 를 구하였다. 또한, $\sigma \rho$ 의 허용오차는 $10^{-7}$ 이며 $\sigma \rho$ 의 결과가 허용오차보다 클 경우 식 (5)과 같이 초기값에서 본함수(5)와 접선의 기울기를 나눈 값 의 차를 이용하여 굴절률을 계산하였다.

$$
\tilde{n}_{2}(\mathrm{i}+1)=\tilde{n}_{2}(\mathrm{i})-\frac{\sigma \rho}{\sigma \rho^{\prime}}
$$

위와 같은 방법으로 구한 굴절률은 그림 $5(\mathrm{~b})$ 에 나타내었 다. $\mathrm{Si}$ 기판의 경우 약 3.41-3.42 범위의 굴절률로 측정되었 고 $\mathrm{Al}_{2} \mathrm{O}_{3}$ 기판의 경우 3.09-3.11로 측정되었으며 $\mathrm{GaAs}$ 기판 의 경우 3.72-3.74 범위의 굴절률이 측정되었다. 높은 주파수 영역에 비하여 낮은 주파수 영역에서 측정된 굴절률이 상대 적으로 일정하지 않은 것으로 측정되었다. 낮은 주파수 대역 인, 파장보다 얇은 두께의 시료에서는 $\mathrm{THz}$ 파가 투과된 양 이 적어 측정된 결과가 일정하지 않는 것으로 나타났으며,

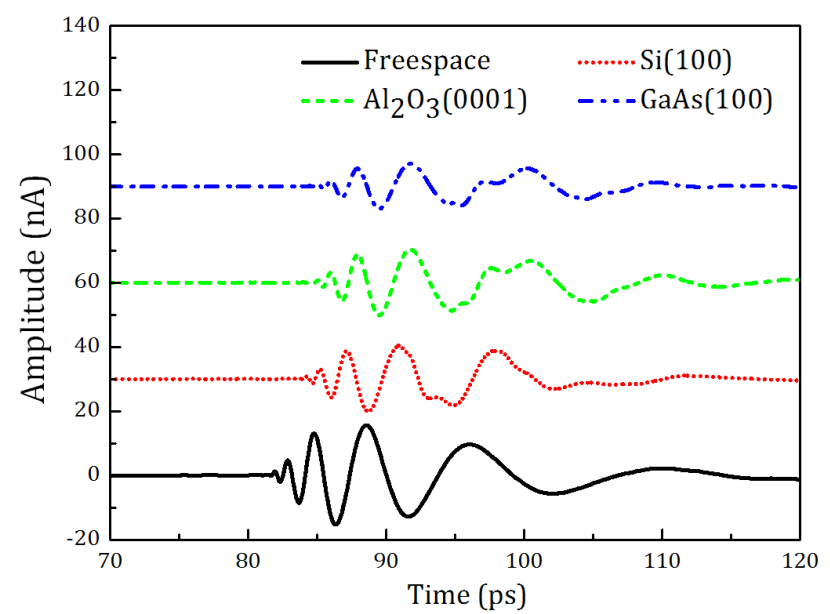

(a)

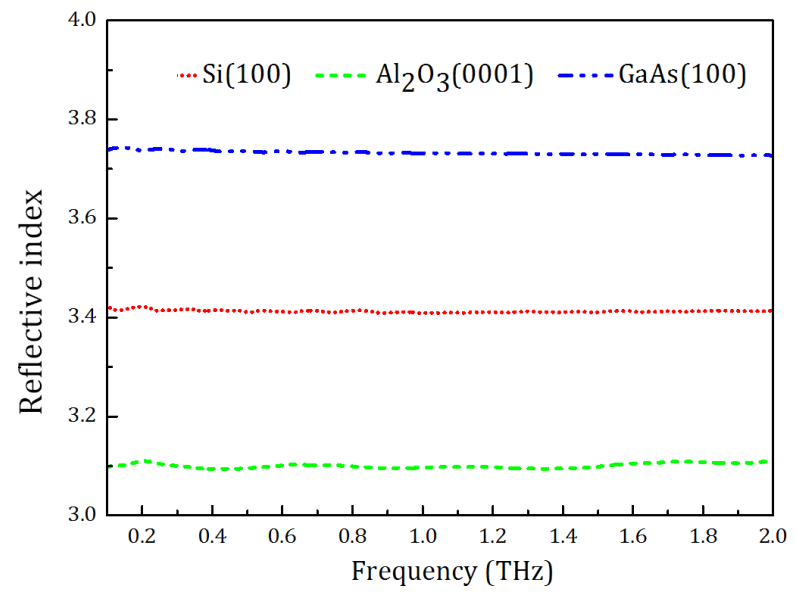

(b)

FIG. 5. (a) Scanned time domain $\mathrm{THz}$ signal of free space (black), $300 \mu \mathrm{m}$ thick $\mathrm{Si}$ (red), $480 \mu \mathrm{m}$ thick $\mathrm{Al}_{2} \mathrm{O}_{3}$ (green) and $350 \mu \mathrm{m}$ thick GaAs (blue) (b) Measured reflective index of the $\mathrm{Si}, \mathrm{Al}_{2} \mathrm{O}_{3}$ and $\mathrm{GaAs}$.

이렇게 변하는 현상은 $\mathrm{THz}$ 파의 파장보다 두꺼운 시료를 이 용하거나 시료에서 반사된 신호를 추가적으로 측정하여 보 정을 해주면 억제시킬 수 있다 ${ }^{[13]}$. 이 결과는 기존의 알려진 바와 비슷한 결과를 가지며 ${ }^{[14,15]}$, 이 결과는 $\mathrm{THz}$ 모듈을 이 용한 분광연구의 응용가능성을 보여준다.

\section{2. 테라헤르츠 영상}

$\mathrm{THz}$ 파의 투과 특성을 이용한 영상을 얻기 위해 그림 6(a) 와 같이 초소형 $\mathrm{THz}$ 모듈을 이용한 영상 시스템을 구성하였 다. 이는 앞서 분광 시스템과 비교하여 $\mathrm{THz}$ 파의 발생기와 측정기는 동일하나 시료의 2 차원 이미지를 얻기 위하여 시 료를 2차원으로 움직일 수 있는 $\mathrm{x}-\mathrm{y}$ 축 스테이지에 위치시켜 실험을 실시하였다. $\mathrm{THz}$ 파가 금속을 투과하지 못하므로 $\mathrm{THz}$ 시간 영역 신호의 피크에서의 샘플이 있는 곳과 없는 곳의 진폭 변화로 샘플의 영상을 측정하였다 ${ }^{[17]}$. 측정에 사용 된 log-spiral 안테나는 다중 피크 특성이 나타나며 앞쪽 피크 


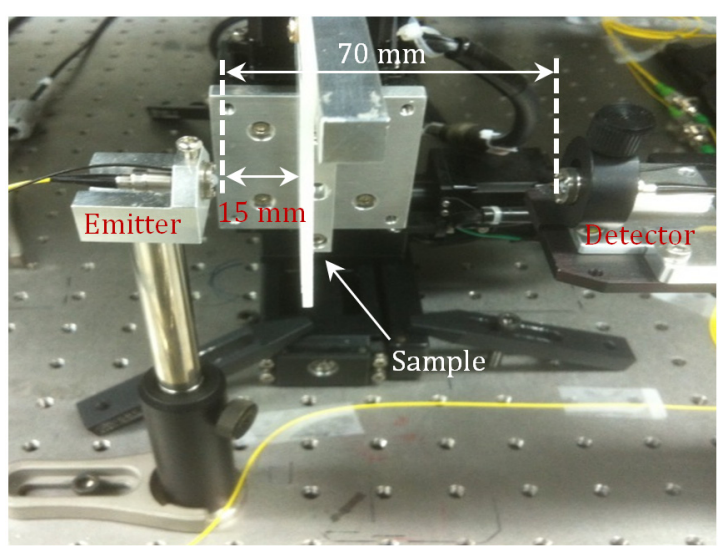

(a)

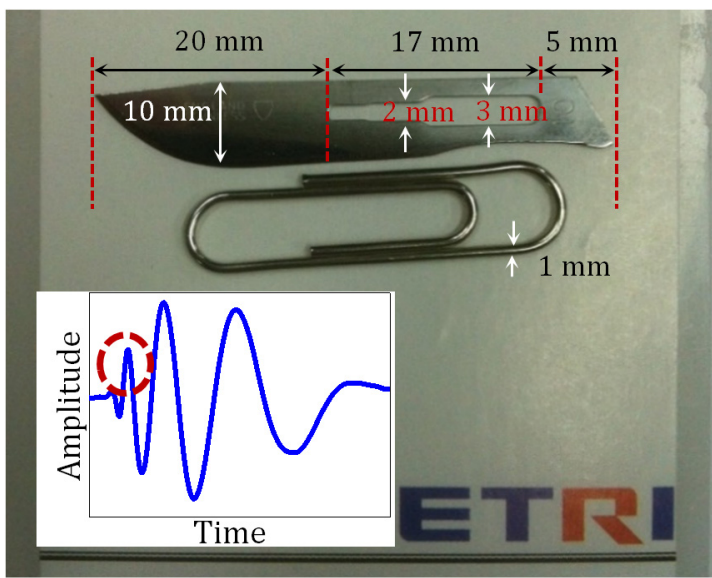

(b)

FIG. 6. Photograph of (a) $\mathrm{THz}$ imaging system and (b) a medical knife and a clip with the inset showing the time delay position used to measure $\mathrm{THz}$ imaging.

에 고 주파수 성분이 모여 있는 특성이 있다. 그러므로 영상 의 해상도를 높이고 SNR(Signal-to-Noise Ratio)을 확보하기 위해 그림 6(b)와 같이 두 번째 피크 지점에서 영상을 측정 하였다. 측정에 사용된 샘플은 그림 6(b)와 같이 의료용 칼과 클립이며 테플론 지지대에 시료를 두고 그 위에 종이로 덮어 시료가 보이지 않도록 하였다. 의료용 칼은 가로, 세로 각각 $45 \mathrm{~mm}, 10 \mathrm{~mm}$ 이고 칼은 중간 부분에 세로로 $2-3 \mathrm{~mm}$ 의 구 멍을 가지고 있으며 클립은 가로, 세로, 두께 각각 $33 \mathrm{~mm}$, $8 \mathrm{~mm}, 1 \mathrm{~mm}$ 이다. $\mathrm{THz}$ 펄스의 발생기와 검출기는 $70 \mathrm{~mm}$ 이 며 발생기에서부터 시료까지 $\mathrm{THz}$ 발생기에 사용한 실리콘 렌즈의 초점거리를 고려하여 $15 \mathrm{~mm}$ 의 거리를 유지하였다. 시료를 $\mathrm{x}-\mathrm{y}$ 축 스테이지에 고정 시켜 $250 \mu \mathrm{m}$ 간격으로 192 $\times 89$ 픽셀을 스캔하였다.

그림 7(a)는 샘플의 영상 결과이다. 결과 이미지의 SNR은 약 $130(21.1 \mathrm{~dB})$ 이며, 샘플의 사이즈가 동일하게 측정 되었으 며, 측정된 이미지에서 의료용 칼의 구멍과 클립의 형태가 정확히 드러나 실제와 유사한 영상 결과를 얻을 수 있었다. 그림 7(b)는 구간 A-B의 프로파일이다. $\mathrm{THz}$ 파가 투과될 때 금속 면의 두께가 두꺼울수록 $\mathrm{THz}$ 파의 투과량은 줄어들고

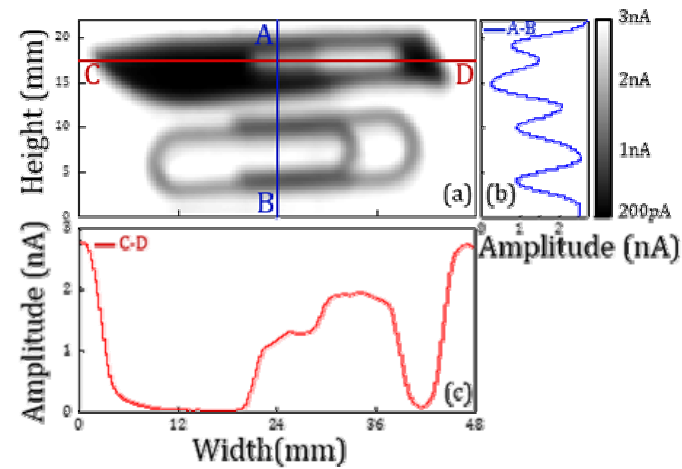

FIG. 7. (a) Raw THz images of a medical knife and a clip, (b) image profile of a line segment (A-B), and (c) image profile of a line segment (C-D).

얇을수록 투과량이 높아짐을 볼 수 있다. 이는 $\mathrm{THz}$ 파의 크 기가 측정된 금속의 두께보다 커 금속의 두께에 따라 $\mathrm{THz}$ 파 투과량이 다르게 나타나는 것을 확인하였다. 그림 7(c)는 구간 C-D의 프로파일이다. 칼의 금속면 부분이 $\mathrm{THz}$ 파의 크 기보다 넓어 $\mathrm{THz}$ 파가 투과되지 않았으며, 칼의 구멍 부분 에서는 $\mathrm{THz}$ 파가 일부 투과됨을 볼 수 있다. 금속면의 넓이 와 두께에 따라 $\mathrm{THz}$ 파의 투과량이 다르게 나타났지만 샘플 의 유무를 충분히 구별할 수 있었다. 이러한 결과를 통해 $\mathrm{THz}$ 파를 이용하여 숨어 있는 물체의 탐지가 가능하며, 선 명하게 영상물을 측정할 수 있음을 보여준다. 그리고 $\mathrm{THz}$ 파를 이용한 영상연구에 초소형의 $\mathrm{THz}$ 모듈의 응용가능성을 보여준다.

\section{IV. 결 론}

본 논문에서는 초소형 크기의 광섬유 결합형 $\mathrm{THz}$ 모듈을 이용하여 THz-TDS 및 영상실험을 수행하였으며 $3 \mathrm{THz}$ 이상 의 수분에 기안한 THz 흡수 피크를 구별하였다. 이 THz-TDS 시스템을 이용하여 $\mathrm{THz}$ 대역에서의 $\mathrm{Al}_{2} \mathrm{O}_{3}$ 의 굴절률과 칼과 클립의 영상을 측정하였다. 굴절률 측정시 신호지속시간 동 안 반사신호가 함께 측정되는 현상으로 인해 다중 반사를 고 려하였으며, Newton-Raphson 법을 이용하여 굴절률을 구하 였다. 각각 측정된 굴절률은 $\mathrm{Si}$ 기판의 경우 약 3.41-3.42, $\mathrm{Al}_{2} \mathrm{O}_{3}$ 기판의 경우 3.09-3.11, GaAs 기판의 경우 3.72-3.74 범위로 측정되어 기존의 알려진 바와 비슷한 결과로 나타남 을 확인할 수 있었다. 영상 실험을 통해 의료용 칼과 클립이 실제와 비슷하게 측정되었다. 이러한 결과는 초소형의 $\mathrm{THz}$ 모듈의 분광 및 영상 측정에 대한 가능성을 보여주고 있다.

앞으로 $\mathrm{THz}$ 분야의 응용은 더욱 커질 것이라 예상되며 그 와 더불어 소형의 $\mathrm{THz}$ 발생 시스템이 요구될 것이다. 본 논 문은 초소형의 광섬유 결합형 $\mathrm{THz}$ 모듈을 이용한 결과라는 데에 의미가 있으며 다양한 연구분야에서의 초소형 모듈을 이용한 $\mathrm{THz}$ 파의 응용가능성을 보였다. 그리고 계속적으로 발전할 소형의 $\mathrm{THz}$ 발생 및 검출분야에 참고자료가 될 것으 로 기대된다. 


\section{References}

1. M. Tonouchi, "Cutting-edge terahertz technology," Nat. Photon. 1, 97-105 (2007).

2. B. Sartorius, H. Roehle, H. Künzel, J. Böttcher, M. Schlak, D. Stanze, H. Venghaus, and M. Schell, "All-fiber terahertz time-domain spectrometer operating at $1.5 \mu \mathrm{m}$ telecom wavelengths," Opt. Express 16, 9565-9570 (2008).

3. S.-P. Han, N. Kim, H. Ko, H.-C. Ryu, J.-W. Park, Y.-J. Yoon, J.-H. Shin, D. H. Lee, S.-H. Park, S.-H. Moon, S.-W. Choi, H. S. Chun, and K. H. Park, "Compact fiber-pigtailed InGaAs photoconductive antenna module for terahertz-wave generation and detection," Opt. Express 20, 18432-18439 (2012).

4. S.-P. Han, H. Ko, N. Kim, H.-C. Ryu, C. W. Lee, Y. A. Leem, D. Lee, M. Y. Jeon, S. K. Noh, H. S. Chun, and K. H. Park, "Optical fiber-coupled InGaAs-based terahertz time-domain spectroscopy system,” Opt. Lett. 36, 3094-3096 (2011).

5. N. Kim, Y. A. Leem, H. Ko, M. Y. Jeon, C. W. Lee, S. P. Han, D. Lee, and K. H. Park, "Widely tunable $1.55 \mu \mathrm{m}$ detuned dual mode laser diode for compact continuous-wave THz emitter," ETRI J. 33, 810-813 (2011).

6. N. Kim, S.-P. Han, H. Ko, Y. A. Leem, H.-C. Ryu, C. W. Lee, D. Lee, M. Y. Jeon, S. K. Noh, and K. H. Park, "Tunable continuous-wave terahertz generation/detection with compact $1.55 \mu \mathrm{m}$ detuned dual-mode laser diode and InGaAs based photomixer," Opt. Express 19, 15397-15403 (2011).

7. N. Kim, H.-C. Ryu, D. Lee, S.-P. Han, H. Ko, K. Moon, J.-W. Park, M. Y. Jeon, and K. H. Park, "Monolithically integrated optical beat sources toward a single-chip broadband terahertz emitter," Laser Physics Letters 10, 085805 (2013).
8. K. H. Park, N. Kim, H. Ko, H.-C. Ryu, J.-W. Park, S.-P. Han, and M. Y. Jeon, "Portable terahertz spectrometer with InP related semiconductor photonic devices," Proc. SPIE 8261, 826103 (2012).

9. A. Danylov, "THz laboratory measurements of atmospheric absorption between $6 \%$ and 52\% relative humidity," Submillimeter-Wave Technology Laboratory University of Massachusetts Lowell, http://stl.uml.edu (2006).

10. X. Xin, H. Altan, A. Saint, D. Matten, and R. R. Alfano, "Terahertz absorption spectrum of para and ortho water vapors at different humidities at room temperature," J. Appl. Phys. 100, 094905-094904 (2006).

11. L. Duvillaret, F. Garet, and J.-L. Coutaz, "A reliable method for extraction of material parameters in terahertz time-domain spectroscopy," IEEE J. Select. Topics Quantum Electron. 2, 739-746 (1996).

12. D.-x. Zhou, E. P. J. Parrott, D. J. Paul, and J. A. Zeitler "Determination of complex refractive index of thin metal films from terahertz time-domain spectroscopy," J. Appl. Phys. 104, 053110-053119 (2008).

13. A. L. Chung, Ph. D. Thesis, University of Southampton (2012), p. 63.

14. D. Grischkowsky, S. Keiding, M. v. Exter, and Ch. Fattinger, "Far-infrared time-domain spectroscopy with terahertz beams of dielectrics and semiconductors," J. Opt. Soc. Am. B 7, 2006-2015 (1990).

15. L. Duvillaret, F. Garet, and J.-L. Coutaz, "A reliable method for extraction of material parameters in terahertz time-domain spectroscopy," IEEE J. Select. Topics Quantum Electron. 2, $739-746$ (1996).

16. M. Herrmann, M. Tani, and K. Sakai, "Display modes in time-resolved terahertz imaging,” Jpn. J. Appl. Phys. 39, 6254 (2000). 